\title{
The Relationships among School Counselors' Vocational Satisfactions, Their School Counseling Self-efficacy Expectations and Delivery System Components
}

\author{
Aliye Işık Tokmak ${ }^{1}$, Ragıp Özyürek ${ }^{2, *}$ \\ ${ }^{1}$ Ozanca Middle School Ozanca Mahallesi, 45580 Gölmarmara, Manisa, Turkey \\ ${ }^{2}$ Psychological Counseling and Guidance Department, Istanbul Medipol University, İstanbul, Turkey
}

Copyright $\mathrm{C} 2018$ by authors, all rights reserved. Authors agree that this article remains permanently open access under the terms of the Creative Commons Attribution License 4.0 International License

\begin{abstract}
In this study, the relationships between school counselors' vocational satisfactions, their school counseling self-efficacy expectations and delivery system components were examined. The research participants of this study were two different samples of counselors who work one of the cities in the west of Turkey. The number of participants in each sample is 150. According to findings, positive correlations were obtained between counselors' vocational satisfactions and their school counseling self-efficacy expectations, and time spent conducting school counseling tasks with students / consultants in face-to-face interaction and negative correlations were found with conducting non-counseling duties. The findings also showed that there may be a positive relationship between vocational satisfactions and self-efficacy expectations and the number of clients participating in individual counseling sessions, the number of individual counseling sessions, the number of large group counseling sessions, the number of periodical individual planning interviewing and a negative relationship the number of small group guidance sessions and the number of conferences the counselors gave to the students. In the discussion section, the similarities between these findings and the findings in the previous studies were discussed and some suggestions were given to the researchers.
\end{abstract}

Keywords Vocational Satisfaction, School Counseling Self-efficacy, Delivery System Components

\section{Introduction}

The National Model, developed by the American School Counselor Association [1-3], is the latest developed comprehensive developmental model. The school counseling program, which was developed in accordance with this model, provides students with various attitudes, knowledge and skills and also measures the effectiveness of this program. With the development of comprehensive developmental models, it is aimed to replace the services and activities based on the traditional approach used by school psychological counsellors with a programmatic approach. With the influence of these models developed in recent years, examining the job satisfaction of school counselors has become an important issue.

As mentioned by DeMato and Curcio [4], job satisfaction of counselors can reduce if they are given tasks which are beyond their abilities at school, if they have to give service to too many students, or if they are given some non-counseling rather than their basic tasks. The researchers examined the issue of job satisfaction in the sample of 301 school counselors working in primary schools. $78.45 \%$ of these counselors are in "gets job satisfaction" and $12.46 \%$ are in "gets job satisfaction a lot" categories. It has been found that these people have direct interaction with students in their school services.

As it was stated by Rayle [5], school counselors are constantly assuming new duties because the tasks they undertake at school involve ambiguities. For example, when there are inconsistencies between the daily tasks they perform, they may face different expectations from administrators, teachers, students and parents day by day. These tasks can remove them from counseling and also increase their work stress. In a sample of 388 school counselors, the researcher examined the relationships among perception of mattering by others, work stress, and job satisfaction. According to the results of the regression analyzes, it was found that mattering by other people in the job environment (students, parents and managers) and work stress predicted job satisfaction $(35 \%$ of total variation explained). It can be said that school counselors who consider themselves important in their job environment have higher job satisfaction and lower work 
stress. As the counselors who implement and complete a comprehensive competency-based guidance program may have increased levels of job satisfaction because they believe that they make some differences in the lives of the people at work, in other words as they perceive that they are valued by others. According to the researcher's comment (p.214), "If school counselors are given ever-increasing number of tasks which are not related to their profession, they may feel work stress more and they may have lower job satisfaction because they cannot meet the expectations of other people at work and they cannot provide effective service to their students."

Kolodinsky, Draves, Schroder, Lindsey and Zlatev [6] worked on the relationships between the use of time, job satisfaction and their inhibition in the work environment of 155 school counselors, and also intended to determine what factors affect job satisfaction. Researchers have stated that in the state of Arizona, comprehensive curriculum-based guidance programs that are very similar to the ASCA National Model have started to be practiced. According to the findings, $55 \%$ of the school counselors stated that the education they got prepared themselves 'good' or 'very good'. These school counselors have stated that they spend on averagely less than $37 \%$ of their time on psychological counseling to students. Only $19.4 \%$ of the respondents said that they devote more than half of their time to counseling to students. On average, they stated that they spent time $21.6 \%$ for teachers, slightly more than $15 \%$ to intervene in crisis, $18.4 \%$ for system support and finally $12.1 \%$ for non-counseling duties. In terms of job satisfaction, approximately $82 \%$ are "mostly satisfied" or "almost completely satisfied". 78.8\% of them said they are "mostly" or "almost completely" satisfied with doing tasks with teachers, $82.6 \%$ with principals and vice-principals, $70 \%$ with local affairs, $74.5 \%$ with parents and $59.4 \%$ with their district managers. It has been found that there is a relationship between these counselors' ways of spending their time and job satisfaction. In detail, there are significant positive correlations between job satisfaction and time spent in counseling with students $(\mathrm{r}=.21)$ and time spent working with teachers $(r=.28)$. It has been also found that there are significant negative correlations between job satisfaction and time spending with intervening in crises $(\mathrm{r}=-.17)$, providing system support $(\mathrm{r}$ $=-.19)$ and doing non-counseling tasks $(r=-.22) .69 \%$ of the school counselors stated that they were getting job satisfaction because they directly give service to students. In terms of the obstacles they have experienced, $61 \%$ of them said that "their tasks are very intense and repressive". For example, they have emphasized that "they try to deal with everything in a day', 'many other tasks that take them away from counseling' and 'there is too much data entry and stationery work' (p. 196). In addition, $15 \%$ of them mentioned that they had incompatibilities with the managers in their school. For example, they have some claims such as "The managers expect a lot from the staff",
"Mandatory meetings prevent counseling", "Managers' respect for counselors is not enough", "I feel guilty on the quiet days when there is crisis" and "People with very little knowledge about our job make decisions and because they set unrealistic deadlines, they cause students to take less service" (p. 196). 40\% of the sample has stated that they can be better trained in certain areas counseling, crisis counseling and meeting with parents. The more counselors spend time with intervening in crises, providing system support and dealing with non-counseling tasks, the less they get job satisfaction. However, they have more job satisfaction when they directly interact with students.

Baggerly and Osborn [7] investigated the relationship between career satisfaction and loyalty in a survey of 1280 school counselors. In terms of career satisfaction, $44.7 \%$ of these school counselors said they were 'up to a degree', and $39.8 \%$ of them said they were 'very' satisfied with their career. Also, career satisfaction has significantly $(\mathrm{p}<.01)$ related to spending time with the tasks related to counseling $(\mathrm{r}=.14)$, non-counseling tasks $(\mathrm{r}=-.19)$, getting supervision from peers $(r=.09)$, and stress $(r=$ -.30). As predictors of career satisfaction; it was found that spending time with the tasks related to counseling $(.028 \%$ of variance explained) the perception of self-competence to perform non-counseling $(.006 \%$ of variance explained), getting supervision from the administers in the area $(.004 \%$ of variance explained) and peers $(.003 \%$ of variance explained) were positive predictors and spending time with non-counseling tasks $(.037 \%$ of variance explained) and stress $(.069 \%$ of variance explained) were negative predictors. According to the findings of Boon, Jaafar and Baba [8] from the Malaysian school counselors "... two factors; the school counselors' own experience and emotional state together with the perceived counseling self-efficacy play a role in contributing to counselors' job satisfaction." (p. 809).

Along with the implementation of comprehensive developmental models such as the ASCA National Model, progress has also been made in the school counseling profession. In this sense, school counselors have come to a turning point [7]. Competence perceptions and job satisfactions of school counselors have become important for successful implementation of these models in schools. School counselors are required to have a quality education, to feel competent while conducting these tasks, and to provide satisfaction in the working environment in order to start the implementation of the comprehensive developmental model in their schools. In this way, they can assume fewer non-counseling tasks.

ASCA National Model [3] consists of four components. These are foundation, delivery, management, and accountability systems. In delivery system, there are direct and indirect student services. As part of direct services, there are school counseling core curriculums, individual student planning and responsive services. These elements 
and strategies require interaction with students. These methods which require interaction with students can be carried out with large group, classroom, small group and individual methods. Indirect student services include referrals, consultation and collaboration elements and strategies.

In the previous studies carried out in Turkey, it was found that school counselors were not competent enough in terms of developing and evaluating school counseling program [9], and they experienced difficulties in their first year after university graduation [10]. It was found that in the sample of the students who were in graduation stage were not competent enough in terms of the methods used by school counselors (group guidance, classroom guidance, small group counseling) [11], they did not have enough practice to make themselves efficient in some applications like school counseling program development, program evaluation, accountability, and psychological test execution [12], and finally during students' counseling or school counseling practices, there were not enough supervision opportunities for them [13]. For these reasons, graduate counselors in Turkey may not feel competent enough which can result in lower job satisfaction and they can assume non-counseling tasks. Therefore, it will be useful to determine the relationships between counselor's job satisfaction and their school counseling self-efficacy expectations and also the work they carry out in accordance with the ASCA National Model delivery system components.

In this study, it was aimed to expand the gathered findings and investigated the relationships between school counselors' vocational satisfaction, their self-efficacy perceptions and delivery system components. For this purpose; (a) the relationship between school counselors' vocational satisfaction and their self-efficacy perceptions and the estimated time spend on face-to-face interaction with students and non-counseling duties were examined. Also, (b) the studies about the methods that counselors use during their interactions with students and the relationship between these two variables (satisfaction and efficacy) were also examined. The methods they use are grouped under the following headings; individual counseling, group counseling, short term interviewing, periodic individual planning interviewing, small group counseling, classroom guidance and school conference. Counselors were asked questions such as the number of sessions or work they did with these methods, the number of clients, the how many hours they spent with them in a week (see Table 2).

Thus, it has been investigated that counselors working in schools have a significant relationship between the tasks they undertake, their vocational satisfaction and their self-efficacy perceptions. Through this research, the findings were obtained on how to train school counselors, on which subjects they should become efficacious, and how they should spend their time in school.

\section{Methodology}

\section{Participants}

School counseling tasks are carried out people working in guidance teacher positioner in Turkey. The participants in this research are counselors working as guidance teachers in İzmir, a big city in the West of Turkey. As there were questions which needed a very long response time, two different questionnaires were prepared and two different samples had to be used. The number of participants in each sample is 150 . In the first sample, there were $90(60 \%)$ female, $60(40 \%)$ male counselors, whereas in the second sample there were $100(66,67 \%)$ female, $50(33,33 \%)$ male counselors. The mean age of the participants was $32.17(\mathrm{sd}=6.42)$ and $35.20(\mathrm{sd}=$ 7.29), respectively. Their mean duration of work in guidance teacher position was $2.77(\mathrm{sd}=2.57)$ and 4.27 $(\mathrm{sd}=3.71)$, respectively.

\section{Instruments}

To collect data in the study Vocational Satisfaction Scale, School Counselor Self-Efficacy Scale, Program Development and Program Evaluation in School Counseling Task Questionnaire and Personal Information Questionnaire were used.

\section{Vocational Satisfaction Scale (VSS)}

For the measurement of VSS was used [14]. The scale which was developed on the basis of Two Factor Theory consists of 20 Likert type questions with five-point rating. In this rating, the grading expressions go from never (1) to always (5). Negative statements in the scale were scored reversely. The rating range varies between 20 and 100 . Construct validity of the scale was determined by factor analysis technique. As a result of the factor analysis, it was determined that the items of the scale were divided into two factors. The first factor is called 'Suitability to Qualifications' and the second factor is called 'Development Request'. Internal consistency coefficient of the scale was calculated by Cronbach alpha formula and it is .90. This coefficient was found to be .91 for first sub-dimension and .75 for second sub-dimension. Also, item total correlations were found above .30 .

\section{School Counselor Self-Efficacy Scale (SC-SEC)}

To measure SC-SEC developed in accordance with Bandura's self-efficacy theory was used. This scale was developed at US [15] and it was adapted to Turkish [16].

SC-SEC, a self-report instrument, consists of a total of 43 items. According to the results of the explanatory factor analysis conducted to test the construct validity of the scale, a structure with five sub-dimensions was found. These sub-dimensions are "Personal and Social Development", "Pioneering and Evaluation", "Career Development and Academic Development", 
"Collaboration" and "Cultural Acceptance". These dimensions are based on the ASCA National Model and the ASCA National Standards [3].

In SC-SEC, school counselors scored their competence beliefs about their current skills from "I do not trust at all" to "I totally trust" on Likert type quintile ratings. The scores range varies from 43 to 215 . Sub-dimensional scores could also be obtained from the scale. Respectively, 12 to 60 for "personal and social development" 9 to 45 for "pioneering and evaluation", 7 to 35 for "career development and academic development", 11 to 55 for "collaboration" and 4 to 20 for "cultural acceptance". High scores on the whole scale or on some dimensions suggest that self-efficacy of school counselors is high [16].

During the Turkish adaptation studies [16], exploratory factor analysis was conducted by using principal component analysis to test construct validity, and after that, the emerging factor structure was tested with confirmative factor analyses (CFA). According to the CFA results, the adaptation study confirmed the five sub-dimensional structure of the measurement tool. The SC-SEC Cronbach alpha coefficients ranged from .74 to .96 .

\section{School Counseling Program Development and Program Evaluation Task Questionnaires 1 and 2}

School Counseling Program Development and Program Evaluation Task Questionnaires 1 and 2 were developed by the authors to identify the practices that school counselors have made regarding program development and program evaluation tasks. While these two questionnaires were being developed, they were based on comprehensive developmental guidance expressions [17, 9]. In addition, while writing items, the items considered to be related to vocational satisfaction or self-efficacy of the school counselors have been identified. In the questionnaires, counselors were offered options for marking the applications they were doing, or various open-ended questions were asked.

Practices carried out at schools were initially divided into four sections. In the first of these sections, there are questions about the development and evaluation of the effectiveness of the school counseling program that a school counselor makes throughout the year. The second section requested some information about the practices on direct interaction methods which are individual counseling, group counseling, short term interviewing, periodical individual planning interviewing, small group guidance (3-7 students), large group guidance (8-12 students), classroom guidance and the work about the school conferences. Definitions of these interaction methods have been made in terms of providing understanding among guidance teachers. In the third section, counselors were asked to indicate how often they had practiced the program development and program evaluation tasks in an academic year or in a term. In the fourth section, they were asked about their views on the counselor education they got.

As it would take a long time to answer the questions, two questionnaires were prepared based on the item numbers and the similarity of content. It takes 15 minutes to complete both questionnaires. Experts were consulted during the preparation of items. Necessary changes have been made on questionnaires in the direction of expert opinions and recommendation.

There are four sections under the School Counseling Program Development and Program Assessment Task Questionnaire 1. In the first section (5 items), there are items related to the development and effectiveness evaluation of the school counseling program conducted by a school counselor throughout the year. In the second section, there are items about individual counseling (12 items) and group counseling (10 items) methods carried out by school counselors. In the third section (20 items), there are some items about school counselors' duties and tasks carried out in an academic year or in some cases in a given period. In the fourth section of the questionnaire (4 items), school counselors were asked to state their opinions on the counselor education they got.

The School Counseling Program Development and Program Assessment Task Questionnaire-2 has questions about five different methods used by school counselors. These questions are to give information about short term interviewing (7 items), periodical individual planning interviewing (7 items), small group counseling (from 3 to 7 students) (8 items), large group guidance (from 8 to 12 students) (8 items), and work about school conferences (6 items) and classroom guidance ( 7 items).

As this research is a part of a larger study and because of space limitation, all the information gathered through this questionnaire was not used. Information used in the study was from the items of the third section of the first questionnaire "Please indicate, approximately what percentage of your time at school do you spend on direct interaction with students throughout the year" and "Please indicate, approximately what percentage of your time at school do you spend with non-counseling duties throughout the year" and the items on the both questionnaires related to the direct interaction methods used by school counselors. Regarding these methods, quantitative measurements like the number of sessions performed by school counselors, the number of clients, and the number of groups were obtained.

\section{Demographic Questionnaire}

To determine some characteristics of the counselors in the sample, Personal Information Form [9], in this form, there are questions about the counselors' age, gender, length of tenure, educational background, departments, school size and the practical courses they took during their undergraduate education. 


\section{Procedure}

The questionnaires were conducted to the school counselors who agreed to participate in-service annual meetings, in-service trainings, seminars and conferences organized by Guidance and Research Centers affiliated to Izmir Governorship and Izmir Provincial Directorate of National Education and also to the school counselors. Furthermore, online questionnaires were applied to school counselors who were also reached via e-mail. After the elimination of the missing or incorrect scales, the data obtained from 300 school counselors were evaluated within the scope of the research. During the implementation of the questionnaires, it was observed that the counselors had difficulties in understanding neither the scales nor the items on the questionnaires and they also made the markings easily.

As mentioned above, it was necessary to prepare two different questionnaires because all the items in the questionnaires would take about 30 minutes to be applied. For this reason, two different questionnaires had to be applied to two different samples. The first questionnaire was applied to the first sample and the second questionnaire was applied to the second sample.

\section{Analyses}

Firstly, descriptive statistics were measured. Since the ranges of the obtained values were too high, the medians had to be given as well as the arithmetic means. In the third section of the first questionnaire, correlation coefficients between the responses obtained from the questions of "the percentage of time spent at school in direct interaction with students" and "the percentage of time spent in school with non-counseling duties" were calculated and correlation coefficients between VSS total scores and SC-SEC subscales were calculated. Similarly, the relationship between work done by direct interaction methods in both questionnaires and vocational satisfaction and school counseling self-efficacy was examined. Pearson correlation was calculated when the quantitative values of the items were suitable for the interval measurement type and Spearman rho correlation analyzes were calculated when the quantitative values of the items were suitable for the ordinal measurement type.

\section{Findings}

The findings in Table 1 were obtained from the participants in the first sample. In the Table, there are answers to the questions of "Please indicate, approximately what percentage of your time at school do you spend with direct interaction with students throughout the year" and "Please indicate, approximately what percentage of your time at school do you spend with non-counseling duties throughout the year" and there are Pearson correlations and descriptive statistics between the scores of VSS and SC-SEC subscales. When the table is examined, the average percentage of time spent by non-counseling duties (20.39) is well below the percentage of time they spend on direct interaction with students (68.45). Another remarkable issue related to descriptive statistics is the high range of the average of both percentages (respectively, 20 to 90 and 0 to 75). Although mean and median values are close to each other, the expressions of counselors are quite different from each other.

Positive and significant relationships were found between the scores obtained from the scales and the percentages of school counselors' time spent on face-to face interaction with students / clients during these tasks and negative and significant relationships were found between the scores and the percentage of conducting non-counseling duties. The majority of the coefficients are significant and medium in size.

Findings related to individual and group counseling in Table 2 were obtained from the first, while findings from other methods were obtained from the participants in the second sample. There are Spearman rho correlations between the scores of the VSS and SC-SEC subscales and the studies on the methods they use in the table. When the table is examined, according to descriptive statistics, of the methods they benefit for direct interaction with students, school counselors scored group counseling and large group guidance methods the least. The most marked are school conferences and individual guidance interviewing. The table also shows that there are big differences between the arithmetic mean and the median, in other words, the range of the number of the sessions done by the counselors, the clients or the work seem to be high.

Table 1. Descriptive statistics and Pearson correlations between how school psychologists spend their time and professional satisfaction and self-efficacy

\begin{tabular}{|c|c|c|c|c|c|c|c|c|c|c|c|c|}
\hline & $\mathrm{n}$ & $\mathrm{M}$ & $\mathrm{Sd}$ & Med. & Min. & Max. & VSS & PSD & PE & CAD & COLL & CA \\
\hline Face-to-face Interaction \% & 139 & 68.45 & 13.36 & 70 & 20 & 90 & $.36^{* *}$ & $.25^{* *}$ & $.20^{*}$ & $.19^{*}$ & $.28^{* *}$ & .15 \\
\hline Non-counseling \% & 123 & 20.39 & 16.27 & 20 & 0 & 75 & $-.35^{* *}$ & $-.22^{*}$ & $-.28^{* *}$ & -.12 & $-.23^{*}$ & $-.21^{*}$ \\
\hline
\end{tabular}

COLL: Collaboration; CAD: Career Development and Academic Development; CA: Cultural Acceptance; PSD: Personal and Social Development; Max.: Maximum; VSS: Vocational Satisfaction Scale; Med.: Median; Min.; Minimum; PE: Pioneering and Evaluation.

$* \mathrm{p}<.05$

$* * \mathrm{p}<.01$ 
There is significant positive relationship between the scores obtained from the scales and the number of clients attending individual counseling sessions, the number of sessions individual counseling, the number of periodical individual planning interviewing hours in a week, the number of large group guidance sessions and there is negative significant relationship between the scores obtained from the scales and the number of groups of small group guidance and the number of conferences given to the students. Significant relationships were obtained mostly between scores of VSS, Personal-Social Development and Collaboration subscales and answers given to items.

\section{Discussion}

Counselors' vocational satisfaction and school counseling self-efficacy had positive relationships with school counseling time spent with students / clients in face-to face interaction and had negative relationships with conducting non-counseling duties. It can be said that the percentage of time spent by non-counseling duties is high. According to the ASCA National Model [3], it was proposed that school counselors would spend $80 \%$ of their time on direct and indirect services. It can be said that in terms of direct interaction percentage of participants in this study, a close percentage $(68.45 \%)$ to this number was obtained. These findings obtained from the Turkish guidance teachers are consistent with previous findings [ 7 , $18,6,19]$.

It may be helpful for researchers to focus on how both school counselors can provide more effective services and how education can make them competent. For this, being accountable and making program evaluation studies are important [20]. During their training, the importance can be given to the extent to which students become competent in the methods they directly interact with.

Studies on the methods by which counselors use by conducting school counseling program are mostly of VSS and SC-SEC subscales which is related to scores of Personal-Social Development and Cooperation subscales. According to this, the numbers of clients participating in individual counseling sessions, the numbers of individual counseling sessions, the numbers of large group guidance sessions, the numbers of periodical individual guidance interviews may show positive correlations with the scores obtained from these scales. However, the number of sessions small group guidance and conference numbers given to students may have a negative relationship with the scores obtained from these scales.

The high range in the obtained values in terms of descriptive statistics can be a sign of not being a standard among the studies carried out by counselors.

\section{Conclusions}

Psychological counselors' providing services to develop students and conducting tasks which consume them less may be related to their vocational satisfaction and self-efficacy perception. Therefore, it can be considered that executing this profession by direct interaction with students and at the same time by avoiding non-counseling duties throughout their careers is very important for counselors. In terms of work carried out, it can be thought that there is not a common consensus among the counselors.

\section{Suggestions}

The definition of the ways in which methods counselors are used by school counselors and how much time they need to spend on these methods will be useful in standardizing the services provided.

The development of counseling skills in counseling training, conducting preventive studies with groups and dealing with individual plans of students can be among the most important topics. For this purpose, how small group counseling, individual planning, and duties related to life skills should be carried out at schools should be further explored. For example, it can be examined whether these studies affect the relationship quality of the principal - school counselor [21].

On the research about school counseling program management models, their relationships can investigate between work on crisis management with small groups, school-wide classroom guidance and conferencing and variables such as occupational satisfaction and burnout. 
Table 2. Descriptive statistics and Spearman rho correlations between vocational satisfaction and self-efficacy and methods that school counselors use to provide school counseling services in the annual framework program.

\begin{tabular}{|c|c|c|c|c|c|c|c|c|c|c|c|c|}
\hline & $\mathrm{n}$ & M & $\mathrm{Sd}$ & Med. & Min. & Max. & VSS & PSD & $\mathrm{PE}$ & CAD & COLL & $\mathrm{CA}$ \\
\hline IC Client Number & 119 & 20.43 & 29.19 & 10 & 2 & 200 & $.26^{* *}$ & .17 & $.20^{*}$ & .15 & $.19^{*}$ & .14 \\
\hline IC Number of Sessions with Clients & 118 & 70.23 & 79.16 & 49 & 2 & 500 & .12 & $.22^{* *}$ & .12 & $.19^{*}$ & $.22^{* *}$ & $.24^{* *}$ \\
\hline GC Group number & 43 & 3.35 & 3.72 & 2 & 1 & 15 & -.18 & -.12 & -.24 & .02 & -.15 & .00 \\
\hline GC Number of Sessions with Group & 42 & 16 & 15.43 & 10 & 3 & 60 & .06 & .03 & -.04 & .19 & -.03 & .11 \\
\hline STI ... Hours in a Week & 51 & 4.71 & 4.17 & 3 & 1 & 15 &,- 18 &, 12 & ,07 &, 11 & ,03 &, 19 \\
\hline Number of PIPI & 139 & 114.93 & 94.98 & 85 & 10 & 600 &,- 08 &,- 01 &,- 07 &, 05 &, 00 &, 00 \\
\hline PIPI Aproximately ... Hours in a Week & 91 & 5.85 & 4.13 & 5 & 1 & 20 &, 06 &, $27^{* *}$ &, 04 &, 14 &, $21^{*}$ &, 11 \\
\hline SGG Group Number & 85 & 13.35 & 17.41 & 8 & 1 & 100 &,$- 24^{*}$ &,- 16 &,- 18 &,- 11 &,- 19 &,- 07 \\
\hline SGG Session Number & 85 & 19.21 & 23.24 & 12 & 1 & 160 &,- 06 &,- 10 &,- 05 &,- 03 &,- 02 &,- 15 \\
\hline LGG Group Number & 49 & 6.57 & 7.08 & 3 & 1 & 33 &, 00 &, 11 &,- 06 &,- 11 &,- 01 &,- 10 \\
\hline LGG Session Number & 49 & 17.76 & 22.20 & 10 & 2 & 100 &, $28^{*}$ &, 20 &, 25 &,- 09 &, $29^{*}$ &, 04 \\
\hline CG Number of Studies & 121 & 16.61 & 15.35 & 10 & 2 & 80 &, 03 &, 04 &, 00 &,- 02 &, 00 &, 09 \\
\hline CG Session Number & 119 & 30 & 32.86 & 20 & 1 & 250 &,- 05 &, 04 &,- 01 &,- 01 &,- 07 &,- 02 \\
\hline Number of Conferences with Students & 136 & 5.96 & 6.89 & 4 & 0 & 60 &,$- 21^{*}$ &,- 10 &, 01 &,- 09 &,- 13 &,- 10 \\
\hline Number of Conferences with Families & 137 & 5.04 & 3.09 & 4 & 1 & 20 &, 03 &, 00 &,- 02 &, 00 &,- 05 &,- 06 \\
\hline
\end{tabular}

CG: Classroom guidance; GC: Group counseling; IC: Individual counseling; LGG: Large group guidance; PIPI: Periodical individual planning interviewing; SC: Number of sessions with clients; SGG: Small group guidance; STI: Short term interviewing.

COLL: Collaboration; CAD: Career Development and Academic Development; CA: Cultural Acceptance; PSD: Personal and Social Development; VSS: Vocational Satisfaction Scale; PE: Pioneering and Evaluation.

P.S.: The number of sessions, groups or counselors was determined according to how much the school psychological counselors performed in a given period. However, the number of people who have been involved in these activities within a week is indicated. However, in both items, the numbers were determined according to how much they did this study in a week.

$* \mathrm{p}<.05$

$* * \mathrm{p}<.01$

\section{Acknowledgements}

F. Polat and E. Ercan were valuable contributors in the process of publishing this article. We appreciate them.

\section{REFERENCES}

[1] ASCA, The ASCA national model: A framework for school counseling programs. Alexandria, VA: Author, 2003..

[2] ASCA, 2009. The ASCA national model. [Online] Retrieved on 25-November-2009, at URL: http://www.ascanationalmodel.org.

[3] ASCA, The ASCA national model: A framework for school counseling programs, Third Edition. Alexandria, VA: Author, 2012..

[4] D. S., DeMato, C. C. Curcio, Job satisfaction of elementary school counselors: A new look, Professional School Counseling, 7, 236-245, 2004.

[5] A.D. Rayle, Do school counselors matter? Mattering as a moderator between job stress and job satisfaction, Professional School Counseling, 9, 206-215, 2006.

[6] P. Kolodinsky, P. Draves, V. Schroder, C. Lindsey, M. Zlatev, Reported levels of satisfaction and frustration by Arizona school counselors:a desire for greater connections with students in a data-driven era, Professional School Counseling, 12, 193-199, 2009.

[7] J. N. Baggerly, D. Osborn, School counselors' career satisfaction and commitment: correlates and predictors. Professional School Counseling, 9, 197-205, 2006.

[8] O. P. Boon, W. W. Jaafar, M. Baba, Factors contributing to job satisfaction among school counselors, Procedia - Social and Behavioral Sciences, 211, 803-810, 2015.

[9] H. Hatipoğlu, Okullarda yürütülen psikolojik danışma ve rehberlik uygulamalarının belirlenmesi ve bazı değişkenler açısından incelenmesi. Unpublished master thesis. Çukurova Üniversitesi Sosyal Bilimler Enstitüsü, 2010.

[10] O. Yerin Güneri, A. Büyükgöze Kavas, S. Koydemir, Professional Development of Turkish School Counselors: The Tough Road from Novice to Expert. F. Korkut-Owen, R. Özyürek, \& D. Owen (Eds.), Developing Counseling and Guidance: Progress in Professionalism, Volume 2, (pp. 139-161), Ankara: Nobel. 2007.

[11] R. Özyürek, School counseling practices in Turkish universities: Recommendations for counselor educators, Eurosian Journal of Educational Research, 39, 175-190, R. 2010.

[12] R. Özyürek, Identification of the Application of School Counseling Practices Carried Out by Students in Counseling and Guidance Undergraduate Program, Education and Science, 156, 160-174, 2010.

[13] R. Özyürek, The supervision opportunities for applied 
school counseling provided to trainees in Turkish universities: A national survey, Turkish Journal of Psychological Counseling and Guidance, 32, 54-63, 2009.

[14] Y. Kuzgun, S. Sevim, Z. Hamamc1, Mesleki doyum ölçeğinin geliştirilmesi. Türk Psikolojik Danışma ve Rehberlik Dergisi, 2(2) 14-18, 1999.

[15] N. Bodenhorn, G. Skaggs, Development of the school counselor self-efficacy scale, Measurement and Evaluation in Counseling and Development, 38, 14-29, 2005.

[16] Z. Erkan, Okul psikolojik danıșmanı öz-yeterliğini yordamada eğitim yaşantılarına ilişsin memnuniyetin rolü. Unpublished master thesis, Bursa: Uludağ Üniversitesi, SBE, 2011.

[17] J. R. Pyne, Comprehensive school counseling programs, job satisfaction, and the ASCA National Model, Professional
School Counseling, 15, 88-97. (doi:10.5330/PSC.n.2011-15.88), 2011.

[18] D. S., DeMato, C. C. Curcio, Job satisfaction of elementary school counselors: A new look, Professional School Counseling, 7, 236-245, 2004.

[19] A. D. Rayle, Do school counselors matter? Mattering as a moderator between job stress and job satisfaction, Professional School Counseling, 9, 206-215, 2006.

[20] R. L. Astramovich, Program evaluation interest and skills of school counselors, Professional School Counseling, 1, 20, (doi: 0.5330/1096-2409-20.1.54), 54-64, 2016.

[21] M. Duslak, Communication factors as predictors of relationship quality: a national study of principals and school counselors, Professional School Counseling, 1, 20, (doi: 10.5330/1096-2409-20.1.115), 115-126, 2016. 